\title{
PREDICTORS FOR LONG-TERM PROGNOSIS AFTER ACUTE CORONARY SYNDROME
}

\section{Krastina I. Doneva-Basheva ${ }^{3}$, Damyan P. Petrov ${ }^{1}$, Tatyana I. Vlaykova ${ }^{2}$, Snezhana T. Tisheva}

Department of Cardiology, Medical University - Pleven

${ }^{1}$ Department of Social Medicine, Medical Faculty, Trakia University Stara Zagora

${ }^{2}$ Department of Chemistry and

Biochemistry, Medical Faculty, Trakia University Stara Zagora

${ }^{3}$ Cardiology Department, Trakia Hospital - Stara Zagora

\section{Corresponding Author:}

Krastina I. Doneva-Basheva,

Department of Cardiology and Intensive

Care,

Trakia Hospital - Stara Zagora

84, Sveti Patriarh Evtimiy Blvd,

Stara Zagora, 6000

Bulgaria

e-mail:dr.doneva@mail.bg

Received: August 20, 2020

Revision received: October 12, 2020

Accepted: May 27, 2021

\section{Summary}

Cardiovascular diseases (CVD) are the leading cause of invalidity and death in developed countries. Among them, the main cause of death is coronary artery disease. In this retrospective study, 172 patients with acute coronary syndrome (STEMI, NSTEMI, UA) are included. They had been hospitalized on an emergency basis in the Cardiology Department, Invasive Sector of Prof. Dr. St. Kirkovich Hospital in Stara Zagora, and the Cardiology Hospital Yambol between January 2009 and February 2010. We found a significant difference in the age at acute coronary syndrome (ACS) occurrence by sex: earlier manifestation was observed in men $(\mathrm{p}=0.018)$. The univariant regression analysis showed that elderly age $(p=0.005$, OR 1.024), glomerular filtration $<90 \mathrm{ml} / \mathrm{h} \quad(\mathrm{p}=0.006$, OR 0.964$)$, GRACE-score $>140 \mathrm{pt}(\mathrm{p}<0.001$, OR 1.045), HF (Killip class $\geq$ II) $(\mathrm{p}=0.002$, OR 15.6) and $\mathrm{EF}<40 \%(\mathrm{p}=0.003$, OR 1$)$ were factors for adverse prognosis in the first, fifth and ninth year. Only GRACE-score was an independent predictor of death obtained by multivariate regression analysis in the study ( $\mathrm{p}=0.002$, OR 1.052). The factors influencing long-term survival adversely after ACS are age, smoking, chronic kidney disease, previously experienced myocardial infarction, diabetes mellitus, three-vessel coronary disease, and decreased systolic function of the left ventricle, and GRACE $>140 \mathrm{p}$.

Keywords: risk factors, survival, mortality, acute coronary syndrome

\section{Introduction}

Cardiovascular diseases (CVD) are the leading cause of invalidity and death in the developed countries $[1,2,27,28]$. The leading cause for death is coronary artery disease and acute coronary syndrome (ACS) in particular. Data from the National Statistical Institute (NSI) show that $65 \%$ of the deaths in Bulgaria are due to CVDs, i.e., approximately 60 thousand deaths per year. Despite the modern treatment methods, the mortality from ACS worldwide remains high in the short- and long-term. There are insufficient data about studies in Bulgaria that identify the factors influencing survival and prognosis in patients after ACS in the short- and long term. Identifying factors influencing survival is essential for a fast and early stratification of the risk at patients with ACS and prompt treatment. 
The Framingham Heart Study is the first-ever long-term epidemiology study [1,2]. It analyses prospectively 5209 men and women aged 30 to 62 , and every two years, the risk factors for cardiovascular diseases have been followed up. The study, published in 1957, defined arterial hypertension as measured systolic arterial pressure $\geq 160 / 95 \mathrm{~mm} \mathrm{Hg}$. The researchers reported that there is a four-fold increase in coronary incidents frequency in people with arterial hypertension. In 1971, the Framingham researchers analyzed 14-year follow-up data and determined a dependency between the output arterial blood pressure and coronary disease incidence. In the first half of the XX century, researchers highlighted the cardiovascular risk factors, namely arterial hypertension, hyperlipidemia, and diabetes mellitus [2,3]. The term "risk factor" was promoted in the medical literature by T. Dawber and U. Kannel in 1961 in their publication about risk factors in coronary heart disease development. In 1976, Kannel and collaborators published the first risk profile $[2,4]$. Twenty years later, Wilson and collaborators published a risk profile for coronary heart disease. It provided a 10-year risk assessment presenting a convenient approach for classifying individuals with a low, moderate, or high risk of coronary heart disease $[2,4,5]$. The latter study underlay the group's risk scale for treating adults in the National Cholesterol Education Program in the United States (NCEP) to assess a 10-year risk, classifying them with a low, moderate, or high risk. During the over 10-year monitoring, the researchers found that arterial hypertension precedes $>50 \%$ of the newly discovered heart failure. Acute myocardial infarction is related to a 6-fold higher risk of developing heart failure. The published data from the prospective follow-up study of this sub-group showed poor prognosis, survival, and increased mortality, with every 2 of 5 men surviving and only one in 10 staying until the tenth year [2].

There are currently many studies proving the role of the risk factors in the genesis of CAD. The global INTERHEART study, covering 27098 participants from 52 countries, demonstrates the connection of nine modifiable risk factors $(>90 \%)$ with the acute myocardial infarction in young and older persons (women and men) in all ethnic groups. The researchers concluded that the average age of first acute myocardial infarction
(AMI) is higher among women compared to men ( 65 vs. 56 years; $\mathrm{P}<0.0001$ ). The modifiable risk factors for both sexes are related to AMI. The presence of risk factors has a higher predictive value in younger patients compared to older patients. The relative risk (PAR) of all nine risk factors exceeds $94 \%$ and is similar in women and men (96 vs. 93\%) [25]. The risk factors (RF) - arterial hypertension (AH), physical inactivity, and alcohol consumption are significantly higher in women than men. Metabolic risk factors greatly increase the risk of AMI, regardless of sex $[24,25]$.

The Romanian register of STEMI for the period 2000-2007 included 9186 consecutive patients. The average age in the group was 63.8 years (SD 11.8) [6]. The risk profile of the patients was: $4986(54.3 \%)$ had arterial hypertension, $1974(21.5 \%)$ had diabetes mellitus, 3545 (38.6\%) had lipid disorders, 4653 (50.7\%) were smokers, and 935 (10.2\%) had had a myocardial infarction. The frequency of arterial hypertension and diabetes mellitus was significantly higher in women, and the higher percentage of smokers was among men. The rate of nosocomial mortality was $12.7 \%$ (1170 death cases). In the prospective study ACSIS conducted in Israel, within the period February-March 2000-2010, every two years, 11536 patients were included with ACS, of whom 4558 were diagnosed with STEMI and the remaining - with NSTEMI. The distribution of the risk factors in patients, randomized in groups by systolic cardiac function and the gravity of the mitral insufficiency, was studied. Of these patients, 4470 (49.7\%) had moderately severe mitral insufficiency $(\mathrm{EF}<50 \%), 854$ $(9.6 \%)$ - severe $(\mathrm{EF}<30 \%)$ and $3659(40.7 \%)$ were with preserved systolic function. The researchers found that older patients $(p<0.001)$ had severe systolic dysfunction and a high rate of comorbidity (arterial hypertension, diabetes mellitus, heart failure, chronic kidney disease, peripheral arterial disease, and cerebrovascular disease) [7]. The one-year mortality significantly correlated with the gravity of pump dysfunction, respectively $36 \%, 4 \%$, and $10 \%$ [7].

The Japanese Multicenter Registry analyzed data from 10,220 patients who passed through a cath-lab for an interventional procedure between 2008 and 2013. The researchers found that women were older, underweight, and more likely 
to have $\mathrm{AH}$, hyperlipidemia, insulin-dependent diabetes mellitus, renal and heart failure than men $(\mathrm{p}<0.001)$ [31].

Multivariate analysis in the general group found that the female gender was an independent predictor of general complications $(\mathrm{p}<0.001)$ and bleeding complications $(\mathrm{p}<0.001)$. A similar trend was observed in the middle-age group $(\geq 55$ and $<75$ years $)$ and the advanced age group $(\geq 75$ years). There were significantly more bifurcation lesions and chronic total occlusions in the men's group on the coronary angiogram than in the women`s group [29]. In the study of Parhomenko et al., patients with diabetes mellitus, renal disease, and known coronary heart disease were found to have a higher mortality rate in NSTEMI [28].

In 2005-2007, a study was conducted in Bulgaria among a sample of the population. It included 4598 healthy residents of large cities (age range 25-74) with at least one cardiovascular risk factor [8]. The general 10-year risk of a fatal cardiovascular event was assessed using the systematic method for evaluating coronary risk (SCORE). The average age of the participants was $56.9 \pm 9.8$. Most participants were within the age group 55-64 years (39.97\%). A high general cardiovascular risk (over 5\%) existed in $48.7 \%$ of the persons in the group. According to the European recommendations, almost half of the participants are considered at high risk for a fatal cardiovascular event over the following ten years. The risk increased with age for both sexes. The riskiest participants (SCORE $\geq 5 \%$ ) were in age groups over 45 years, particularly over 55 years. The highest risk existed in $24.3 \%$ of the subjects examined within the range $45-54$ years and in more than half of the participants aged 55 to 64 years $(58.5 \%$ and $28 \%$, respectively). The common cardiovascular risk in men was significantly higher than the risk in women aged 35-44 and 45-54 (P\%), 001 for both). Almost half of the men aged $45-54$ years $(42.4 \%)$ had a high common risk (SCORE $\geq 5 \%$ ). The overall cardiovascular risk increased sharply in the age groups over 45 years. Only $6.6 \%$ of men aged 65-74 years were at a low and medium common risk (SCORE <5\%). However, the percentage of participants with a very high risk (SCORE $\geq 15 \%$ ) was $46.6 \%$, i.e., almost half of men over 65 years were at a very high common risk of developing a fatal cardiovascular event over the following ten years [8]. The results of the most extensive epidemiological studies held in Bulgaria - the Sofia Heart Study (19941999), the Bulgaria Heart Study 1998, and the CINDI study showed that the spread of the major risk factors was significantly higher among the Bulgarian population compared to the other European countries [30].

In a study of Kanazirev, following up prospectively for two years 145 persons with left ventricular dysfunction and heart failure after AMI at standard outpatient therapy and retrospectively for eight years, it was determined overall mortality of $14.9 \%$ in the first year, $32.12 \%$ - the second year, $55.1 \%$ - the third year, $71.43 \%$ - the fifth year and $91.84 \%$ in the eighth year. Cardiovascular mortality accounted for a significant part of the overall mortality. By the end of the follow-up, the cumulative cardiovascular mortality accounted for $73.25 \%$ of the overall mortality. The most significant part of cardiovascular mortality was sudden cardiac death $(61.19 \%)$ and $46.51 \%$ of the overall mortality rate in the eighth year. Acute heart failure was the second most significant cause of death, and at the end of the follow-up in the eighth year, it was $18.56 \%$. The fatal myocardial infarction was the cause of death in $10.44 \%$ of the cases by the end of the follow-up period. The highest frequency of death occurrence was during the first 40 months, then the mortality curve decreased significantly [9].

The purpose of the present study was to define factors influencing the short-term (1-year) and long-term (9-year) prognosis in patients with ACS by studying many indicators: demographic (sex, age), clinical laboratory (creatinine, glomerular filtration, LDL, HDL, TG), clinical (heart rate, arterial hypertension, acute left ventricular heart failure - Killip II-IV, ST deviation of ECG), smoking, echocardiography (EF $(</>40 \%$, mitral insufficiency), concomitant diseases (diabetes mellitus, stable angina pectoris, experienced ACS, rhythm/conduction disorders, cerebrovascular disease).

\section{Materials and Methods}

A retrospective study was conducted on 172 patients with acute coronary syndrome (STEMI - 103 patients, NSTEMI - 25 patients, UA 44 patients) hospitalized on an emergency 
basis in the Invasive cardiology department of the University Hospital in Stara Zagora and the Cardiology Clinics in Yambol between January 2009 and February 2010. The criteria for inclusion, distribution, and treatment of the patients in the groups are consistent with the guidelines of ESC (2010). The GRACE-score of all patients was calculated for assessing the nosocomial and 6-month mortality. The patients were followed up prospectively during the $1 \mathrm{st}$ year, and retrospectively in the $3 \mathrm{rd}$, 5th, and 9th year after ACS. The risk factors for analyzing the mortality included age, sex, diagnosis, arterial hypertension, diabetes mellitus, dyslipidemia, smoking, CAD family history, experienced AMI, decreased systolic function of the left ventricle, and kidney function.

The statistical analyses were performed by specialized statistical software SPSS v16.0 (IBM, Chicago, IL). We used standard statistical descriptive methods to analyze demographic and clinical characteristics, laboratory, echocardiography, and angiography indicators. The dichotomous variables were reported as numbers and percentages and were compared using $\mathrm{x} 2$ tests, and univariant and multivariate regression analyses were performed to identify the significant risk factors. The Spearman's rank correlation was also applied to find out correlations between the continuous variables. Cox regression was used to identify independent prognostic factors.

\section{Results}

The distribution of the patients by demographic criteria and risk factors is shown in Table 1.
Clinical-demographic characteristics of patients with ACS with ST-elevation are presented in Table 2.

Clinical-demographic characteristics of patients with ACS without ST elevation are presented in Table 3.

Demographic characteristics, risk factors, clinical and instrumental data of the patients in the three groups are shown in Table 4.

The average age of the hospitalized patients with ACS was $61.5 \pm 11.9$ (32.0-86.0) and $60.9 \pm 12.1(32.0 ; 85.0)$ with a STEMI diagnosis. The group of men was twice as big as the group of women and approximately five years younger. Among the hospitalized patients with NSTEMI and unstable angina (UA), the men were 50\% more, as seen from the above data. The average age of the NSTEMI group was $66.2 \pm 12.3$ and $60.2 \pm 10.7$ for the UA group. The age of women with NSTEMI was $69.9 \pm 15.3$, and of men $64.5 \pm 10.6$, and the same tendency was seen in the group with unstable angina pectoris: $63.7 \pm 8.6$ for men and $58.6 \pm 11.3$ for women.

A statistically significant age difference $(p=0.018)$ was found at the occurrence of an acute coronary event in women $(n=59)$ and men $(n=113)$. No statistically significant age difference was found by diagnosis $(\mathrm{p}=0.097)$. The age of onset of a coronary incident was significantly higher in women, regardless of the diagnosis $(p=0.09)$. We found a relation between the average age and arterial hypertension $(\mathrm{p}<0.001)$ as a risk factor regardless of sex. In $62.8 \%$ (91) of the men, arterial hypertension was present, while the women's percentage was $37.2 \%(54)$. Smoking rates in the group was as follows: non-smokers $(67.7 \pm 11.0(34.0 ; 86.0))$,

Table 1. Output characteristics of patients: modifiable and non-modifiable risk factors

\begin{tabular}{ll}
\hline Risk factors & Number (percentage) \\
\hline Sex & Women - 59 (34.3\%); Men - 113(65.7\%) \\
\hline Age & $61.5 \pm 11.9(32.0-86.0)$ \\
\hline Arterial hypertension & $145(84.3 \%)$ \\
\hline Dyslipidemia & $101(58.7 \%)$ \\
\hline Overweight; Obesity & $85(69.1 \%) ; 38(30.9 \%)$ \\
\hline Smoking & $62(36 \%)$ \\
\hline Diabetes mellitus & $45(26.2 \%)$ \\
\hline Family history & $43(25)$ \\
\hline Experienced ACS & $27(15.7 \%)$. \\
\hline
\end{tabular}


Table 2. Clinical-demographic characteristics of patients with ACS with ST-elevation

\begin{tabular}{ll}
\hline Demographic and clinical indicators & STEMI $(\mathrm{n}=103)$ \\
\hline Sex & \\
Women & $37(35.9)$ \\
Men & $66(64.1)$ \\
\hline Age & $60.9 \pm 12.1(32.0 ; 85.0)$ \\
General: & $63.6 \pm 11.1(42.0 ; 85.0)$ \\
Women & $59.4 \pm 12.5(32.0 ; 83.0)$ \\
Men & $6(5.8)$ \\
\hline Experienced ACS & $25(24.3)$ \\
\hline Family history & \\
\hline Smoking & $37(35.9)$ \\
Smokers & $5(4.9)$ \\
Ex-smokers & $58(56.3)$ \\
Non-smokers & $3(2.9)$ \\
Failed to indicate & $56(54.4)$ \\
\hline Dyslipidemia & \\
\hline Arterial hypertension & $34(91.9)$ or $(40.0)^{*}$ \\
Women & $51(77.3)$ or $(60.0)$ \\
Men & \\
\hline Diabetes mellitus (known and newly discovered) & $17(16.5)$ \\
Non-insulin-dependent diabetes mellitus & $6(5.8)$ \\
Insulin-dependent diabetes mellitus & $5(4.9)$ \\
NGT & $30.0 \pm 4.3(19.0 ; 55.4)$ or 26.5(19.0; 55.4) \\
\hline BMI** & $60.9 \pm 257(4.8 ; 108.6)$ \\
\hline Glomerular filtration & $73.7 \pm 273(11.4 ; 158.8)$ \\
Women &
\end{tabular}

ex-smokers $\quad(57.9 \pm 7.9(46.0 ; 73.0))$ smokers $(53.6 \pm 8.5(32.0 ; 71.0))$. No dependency was observed between smoking and the type of ACS $\left(\chi^{2}(2)=2.747 ; p=0.253\right)$. We found a dependency in the subgroup distribution by age $\left(\chi^{2}=57.602\right.$; $\mathrm{p}<0.001)$. There were more smokers in the three age groups under 60 and significantly more nonsmokers in the age groups over 70. Comparison between sexes showed that smoking as a risk factor was significantly more widely spread among men $(p<0.001)$. There was a significant correlation between the number of patients with known stable angina pectoris in the group with unstable angina pectoris, unlike the group with STEMI $\left(\chi^{2}(2)=16.159 ; p<0.001\right)$. The presence of risk factors among the patients was the following: with one RF - 15 (8.7\%), with two RFs - 47 (27.3\%), and with three and more $106(61.6 \%)$. The highest number was that of patients with $>3$ RFs with STEMI, followed by those with UAP and NSTEMI.

No difference was observed in the frequency of diabetes mellitus for both sexes $(\chi 2(1)=0.275$; $\mathrm{p}=0.600)$ and diagnosis $-\chi 2(2)=1.929 ; \mathrm{p}=0.381$. By age distribution, significantly more patients with diabetes mellitus were found in the age group 70-79 years $-(\chi 2(5)=13.923 ; p=0.017)$ compared to younger patients. The highest value of the total cholesterol and LDL was in the group with STEMI with no significant difference from the other two groups. No significant difference was found in the total cholesterol value by sex $(\mathrm{p}=0.2)$ and the groups $(\mathrm{p}=0.14)$. No significant difference was found in the levels of LDL by sex $(\mathrm{p}=0.17)$ and by diagnosis $(\mathrm{p}=0.3)$, as well as at $\mathrm{TG}, \mathrm{p}=0.1$ and $\mathrm{p}=0.36$, respectively. The HDL value differs significantly in the groups with STEMI and UAP $(p=0.005)$. Our group's total cholesterol and LDL values did not correlate with BMI using Spearman's rank correlation coefficient. We found a low positive correlation between the increased TG and BMI (Rho=$0.292, \mathrm{p}<0.001)$ and a low negative correlation between HDL and BMI (Rho=-0.159, $\mathrm{p}=0.039)$. 
Table 3. Clinical-demographic characteristics of patients with ACS without ST elevation

\begin{tabular}{|c|c|c|}
\hline & NSTEMI $(n=44)$ & $\mathrm{UA}(\mathrm{n}=25)$ \\
\hline $\begin{array}{l}\text { Sex } \\
\text { Women } \\
\text { Men }\end{array}$ & $\begin{array}{l}14(31.8) \\
30(68.2)\end{array}$ & $\begin{array}{l}8(32.0) \\
17(68.0)\end{array}$ \\
\hline $\begin{array}{l}\text { Age } \\
\text { General: } \\
\text { Women } \\
\text { Men }\end{array}$ & $\begin{array}{l}66.2 \pm 123(42.0 ; 86.0) \\
69.9 \pm 153(42.0 ; 82.0) \\
64.5 \pm 10.6(48.0 ; 86.0)\end{array}$ & $\begin{array}{l}60.2 \pm 10.7(39.0 ; 86.0) \\
63.7 \pm 8.6(49.0 ; 76.0) \\
58.6 \pm 113(39.0 ; 86.0)\end{array}$ \\
\hline $\begin{array}{l}\text { Experienced ACS } \\
\text { Previous coronary angiography }\end{array}$ & $10(40.0)$ & $11(25.0)$ \\
\hline Family history & $6(24.0)$ & $12(27.3)$ \\
\hline $\begin{array}{l}\text { Smoking } \\
\text { Smoker } \\
\text { Ex } \\
\text { Non-smoker } \\
\text { Failed to indicate }\end{array}$ & $\begin{array}{l}6(24.0) \\
5(20.0) \\
14(56.0)\end{array}$ & $\begin{array}{l}19(43.2) \\
5(11.4) \\
20(45.5)\end{array}$ \\
\hline Dyslipidemia & $28(63.6)$ & $17(68.0)$ \\
\hline $\begin{array}{l}\text { Arterial hypertension } \\
\text { Women } \\
\text { Men }\end{array}$ & $\begin{array}{l}7(87.5) \text { or }(33.3) \\
14(82.4) \text { or }(66.7)\end{array}$ & $\begin{array}{l}13(92.9) \text { or }(33.3) \\
26(86.7) \text { or }(66.7)\end{array}$ \\
\hline $\begin{array}{l}\text { Diabetes mellitus (known and newly discovered) } \\
\text { Non-insulin-dependent diabetes mellitus } \\
\text { Insulin-dependent diabetes mellitus } \\
\text { NGT }\end{array}$ & $\begin{array}{l}4(16.0) \\
2(8.0) \\
-\end{array}$ & $\begin{array}{l}11(25.0) \\
4(9.1) \\
2(8.0)\end{array}$ \\
\hline $\mathrm{BMI} * *$ & $28.3 \pm 4.3(21.5 ; 41.9)$ & $27.0 \pm 3.3(19.0 ; 33.8)$ \\
\hline $\begin{array}{ll}\text { Glomerular filtration } & \\
\text { Women } & 62.9 \pm 31.3(28.2 ; 125.0) \\
\text { Men } & 70.9 \pm 19.1(40.6 ; 105.5)\end{array}$ & $\begin{array}{l}62.3 \pm 10.6(52.8 ; 91.5) \\
83.7 \pm 16.2(57.9 ; 116.6)\end{array}$ & \\
\hline
\end{tabular}

Table 4. Demographic characteristics, risk factors, clinical and instrumental data of the patients in the three groups

\begin{tabular}{lllll}
\hline & Total & STEMI & NSTEMI & UA \\
\hline Number of patients & 172 & $103(59.9 \%)$ & $25(14.5 \%)$ & $44(25.6 \%)$ \\
\hline Sex (\% men) & & $66(64.1 \%)$ & $17(68.0 \%)$ & $30(68.2 \%)$ \\
\hline Age & $61.5 \pm 11.9$ & $60.9 \pm 12.1$ & $66.2 \pm 12.3$ & $60.2 \pm 10.7$ \\
& $(32.0-86.0)$ & $(32.0-85.0)$ & $(42.0-86.0)$ & $(39.0-86.0)$ \\
\hline Risk factors: & & & & $4(9.1 \%)$ \\
1 RF (\% yes) & $15(8.7 \%)$ & $9(8.7 \%)$ & $2(8.0 \%)$ & $10(22.7 \%)$ \\
2 RF (\% yes) & $47(27.3 \%)$ & $29(28.2 \%)$ & $8(32.0 \%)$ & $30(68.2 \%)$ \\
\hline 3 RF (\% yes) & $106(61.6 \%)$ & $61(59.2 \%)$ & $15(60.0 \%)$ & $2(4.5 \%)$ \\
\hline Known heart failure & & & $3(12.0 \%)$ & $32(72.7 \%)$ \\
$>$ II F.C. & $11(6.4 \%)$ & $6(5.8 \%)$ & $15(60.0 \%)$ & $3(6.8 \%)$ \\
\hline Previous stable angina pectoris & $86(50.0 \%)$ & $39(37.9 \%)$ & $2(8.0)$ & $4(9.1 \%)$ \\
\hline Anemia & $19(11.1 \%)$ & $14(13.6 \%)$ & $1(4.0)$ & $9(8.7 \%)$ \\
Cerebrovascular disease & $14(8.3 \%)$ & & & \\
\hline
\end{tabular}




\begin{tabular}{|c|c|c|c|c|}
\hline \multicolumn{5}{|l|}{ Laboratory indicators: } \\
\hline Acute hypertension & $\begin{array}{l}5.4 \pm 1.7 \\
(1.4-16.1)\end{array}$ & $\begin{array}{l}5.6 \pm 1.9 \\
(1.4-16.1)\end{array}$ & $\begin{array}{l}5.3 \pm 1.6 \\
(3.0-11.1)\end{array}$ & $\begin{array}{l}5.0 \pm 1.0 \\
(3.0-7.8)\end{array}$ \\
\hline LDL & $\begin{array}{l}3.1 \pm 1.4 \\
(0.7-12.1)\end{array}$ & $\begin{array}{l}3.3 \pm 1.6 \\
(1.2-12.1)\end{array}$ & $\begin{array}{l}3.0 \pm 1.4 \\
(0.7-8.0)\end{array}$ & $\begin{array}{l}2.8 \pm 0.9 \\
(1.2-5.0)\end{array}$ \\
\hline HDL & $\begin{array}{l}1.7 \pm 0.4 \\
(0.7-3.3)\end{array}$ & $\begin{array}{l}1.8 \pm 0.4 \\
(08-33)\end{array}$ & $\begin{array}{l}1.6 \pm 0.3 \\
(12-2.5)\end{array}$ & $\begin{array}{l}1.6 \pm 0.4 \\
(07-28)\end{array}$ \\
\hline TG & $\begin{array}{l}1.4 \pm 0.9 \\
(0.3-5.8)\end{array}$ & $\begin{array}{l}1.3 \pm 0.9 \\
(0.3-5.8)\end{array}$ & $\begin{array}{l}1.6 \pm 1.0 \\
(0.6-3.7)\end{array}$ & $\begin{array}{l}1.4 \pm 0.9 \\
(0.3-3.8)\end{array}$ \\
\hline Creatinine & $\begin{array}{l}107.2 \pm 85.8 \\
(50.0-815.7)\end{array}$ & $\begin{array}{l}117.1 \pm 107.8 \\
(54.2-815.7)\end{array}$ & $\begin{array}{l}101.1 \pm 30.5 \\
(50.0-163.5)\end{array}$ & $\begin{array}{l}86.4 \pm 12.7 \\
(63.0-124.2)\end{array}$ \\
\hline CPK & $\begin{array}{l}723.9 \pm 1179.4 \\
(25.0-6491.0)\end{array}$ & $\begin{array}{l}1011.5 \pm 1405.5 \\
(64.0-6491.0)\end{array}$ & $\begin{array}{l}506.9 \pm 575.7 \\
(25.0-1827.0)\end{array}$ & $\begin{array}{l}161.2 \pm 297.1 \\
(34.0-2020.0)\end{array}$ \\
\hline CPK-MB & $\begin{array}{l}103.2 \pm 161.2 \\
(1.2-1108.1)\end{array}$ & $\begin{array}{l}143.5 \pm 191.3 \\
(2.5-1108.1)\end{array}$ & $\begin{array}{l}74.4 \pm 86.4 \\
(2.7-270.7)\end{array}$ & $\begin{array}{l}25.5 \pm 42.8 \\
(1.2-251.2)\end{array}$ \\
\hline Tn I & $\begin{array}{l}6.9 \pm 27.8 \\
(0.01-226.0)\end{array}$ & $\begin{array}{l}8.5 \pm 34.6 \\
(0.01-226.0)\end{array}$ & $\begin{array}{l}5.4 \pm 8.2 \\
(0.09-28.1)\end{array}$ & $\begin{array}{l}2.6 \pm 3.2 \\
(0.1-9.6)\end{array}$ \\
\hline \multicolumn{5}{|l|}{ ECG: } \\
\hline ST-elevation & $96(55.8 \%)$ & $90(87.4 \%)$ & $4(16.0 \%)$ & $2(4.5 \%)$ \\
\hline ST depression & $31(18.0 \%)$ & $8(7.8 \%)$ & $13(52.0 \%)$ & $10(22.7 \%)$ \\
\hline Neg. T wave & $39(22.7 \%)$ & $9(8.7 \%)$ & $9(36.0 \%)$ & $21(47.7 \%)$ \\
\hline Pathological Q-waves & $51(29.7 \%)$ & $35(34.0 \%)$ & $6(24.0 \%)$ & $10(22.7 \%)$ \\
\hline Without ST-T changes & $5(2.9 \%)$ & $0(0.0 \%)$ & $1(4.0 \%)$ & $4(9.1 \%)$ \\
\hline \multicolumn{5}{|l|}{ Rhythm/conduction disorders: } \\
\hline Full left bundle branch block & $4(2.3 \%)$ & $1(1.0 \%)$ & $1(4.0 \%)$ & $2(4.5 \%)$ \\
\hline Right bundle branch block & $8(4.7 \%)$ & $3(2.9 \%)$ & $4(16.0 \%)$ & $1(2.3 \%)$ \\
\hline Left anterior hemiblock & $17(9.9 \%)$ & $9(8.7 \%)$ & $3(12.0 \%)$ & $5(11.4 \%)$ \\
\hline AV block & $13(7.6 \%)$ & $10(9.7 \%)$ & $1(4.0 \%)$ & $2(4.5 \%)$ \\
\hline Atrial fibrillation/flutter & $19(11.0 \%)$ & $10(9.7 \%)$ & $4(9.1 \%)$ & $5(20.0 \%)$ \\
\hline Ventricular tachycardia & $7(4.1 \%)$ & $6(5.8 \%)$ & $1(2.3 \%)$ & - \\
\hline SP & $\begin{array}{l}137.4 \pm 26.8 \\
(70.0-260.0)\end{array}$ & $\begin{array}{l}138.9 \pm 29.7 \\
(70.0-260.0)\end{array}$ & $\begin{array}{l}141.8 \pm 26.4 \\
(100.0-210.0)\end{array}$ & $\begin{array}{l}131.4 \pm 18.0 \\
(80.0-170.0)\end{array}$ \\
\hline DP & $\begin{array}{l}85.0 \pm 15.4 \\
(40.0-143.0)\end{array}$ & $\begin{array}{l}86.0 \pm 17.2 \\
(40.0-143.0)\end{array}$ & $\begin{array}{l}85.8 \pm 14.2 \\
(60.0-118.0)\end{array}$ & $\begin{array}{l}82.3 \pm 10.8 \\
(50.0-106.0)\end{array}$ \\
\hline HR & $\begin{array}{l}79.0 \pm 16.1 \\
(40.0-145.0)\end{array}$ & $\begin{array}{l}80.2 \pm 16.3 \\
(40.0-135.0)\end{array}$ & $\begin{array}{l}78.6 \pm 12.9 \\
(59.0-104.0)\end{array}$ & $\begin{array}{l}76.3 \pm 17.1 \\
(50.0-145.0)\end{array}$ \\
\hline \multicolumn{5}{|l|}{ LVHF } \\
\hline \multicolumn{5}{|l|}{$\begin{array}{l}\text { Echocardiography indicators: } \\
\text { EDV }\end{array}$} \\
\hline ESV & $\begin{array}{l}50.3 \pm 7.5 \\
(24.0-80.0) \\
34.0 \pm 7.8\end{array}$ & $\begin{array}{l}50.7 \pm 7.4 \\
(31.0-80.0) \\
35.0 \pm 7.4\end{array}$ & $\begin{array}{l}48.5 \pm 8.1 \\
(24.0-66.0) \\
35.4 \pm 8.1\end{array}$ & $\begin{array}{l}50.3 \pm 7.4 \\
(39.0-71.0) \\
34.6 \pm 8.6\end{array}$ \\
\hline $\begin{array}{l}\mathrm{EF}(\%): \\
>55-50 \%\end{array}$ & $(21.0-60.0)$ & $(21.0-55.0)$ & $(23.0-55.0)$ & $(23.0-60.0)$ \\
\hline $49-40 \%$ & $96(55.8 \%)$ & $49(47.6 \%)$ & $12(48.0)$ & $35(79.5 \%)$ \\
\hline $39-30 \%$ & $55(32.0 \%)$ & $39(37.9 \%)$ & $11(44.0)$ & $5(11.4 \%)$ \\
\hline$<30 \%$ & $9(5.2 \%)$ & $6(5.8 \%)$ & $1(4.0)$ & $2(4.5 \%)$ \\
\hline
\end{tabular}




\begin{tabular}{|c|c|c|c|c|}
\hline \multicolumn{5}{|l|}{ Coronary anatomy: } \\
\hline $\mathrm{LM}$ & $18(10.5 \%)$ & $9(8.7 \%)$ & $4(16.0 \%)$ & $5(11.4 \%)$ \\
\hline LAD & $96(55.8 \%)$ & $62(60.2 \%)$ & $17(68.0 \%)$ & $17(38.6 \%)$ \\
\hline $\mathrm{LCx}$ & $64(37.2 \%)$ & $34(33.0 \%)$ & $17(68.0 \%)$ & $13(29.5 \%)$ \\
\hline $\mathrm{RCA}$ & $88(51.2 \%)$ & $57(55.3 \%)$ & $18(72.0 \%)$ & $13(29.5 \%)$ \\
\hline Single-vessel disease & $51(29.7 \%)$ & $40(38.8 \%)$ & $4(16.0 \%)$ & $7(15.9 \%)$ \\
\hline Two-vessel disease & $46(26.7 \%)$ & $33(32.0 \%)$ & $7(28.0 \%)$ & $6(13.6 \%)$ \\
\hline Three-vessel disease & $48(27.9 \%)$ & $26(25.2 \%)$ & $13(52.0 \%)$ & $9(20.5 \%)$ \\
\hline $\begin{array}{l}\text { Directed for coronary artery } \\
\text { bypass }\end{array}$ & $14(8.1 \%)$ & $10(9.7 \%)$ & - & $4(9.1 \%)$ \\
\hline Nosocomial mortality & $13(7.6 \%)$ & $11(10.7 \%)$ & - & $2(4.5 \%)$ \\
\hline \multicolumn{5}{|l|}{ Outpatient therapy: } \\
\hline $\mathrm{ACE} / \mathrm{ARB}$ & $81(47.1 \%)$ & $34(33.0 \%)$ & $18(72.0 \%)$ & $29(65.9 \%)$ \\
\hline Beta-blockers & $65(37.8 \%)$ & $22(21.4 \%)$ & $12(48.0 \%)$ & $31(70.5 \%)$ \\
\hline Statin & $31(18.0 \%)$ & $7(6.8 \%)$ & $9(36.0 \%)$ & $15(34.1 \%)$ \\
\hline Acetylsalicylic acid & $48(27.9 \%)$ & $17(16.5 \%)$ & $12(48.0 \%)$ & $19(43.2 \%)$ \\
\hline Clopidogrel & $11(6.4 \%)$ & $4(3.9 \%)$ & $4(16.0 \%)$ & $3(6.8 \%)$ \\
\hline Trimetazidine & $9(5.2 \%)$ & $5(4.9 \%)$ & $2(8.0 \%)$ & $2(4.5 \%)$ \\
\hline High ceiling diuretics & $10(5.8 \%)$ & $4(3.9 \%)$ & $4(16.0 \%)$ & $2(4.5 \%)$ \\
\hline \multicolumn{5}{|l|}{ GRACE } \\
\hline$<=108 \mathrm{p}-$ & $89(51.7 \%)$ & 25 & 64 & 89 \\
\hline $109-140 \mathrm{p}$ & $51(29.7 \%)$ & 17 & 34 & 51 \\
\hline$>140 \mathrm{p}-$ high & $32(18.6 \%)$ & 17 & 15 & 32 \\
\hline
\end{tabular}

Therefore, in patients with high BMI, there were decreased HDL levels. The heart rate was significantly higher in women $(\mathrm{p}=0.045)$.

No significant difference in creatinine levels was observed for the three diagnoses $(p=0.1)$. The average glomerular filtration, calculated by MDRD, was $71.8 \mathrm{ml} / \mathrm{min}$ (Mean \pm SD $71.8 \pm 24.1$ (5.1-158.8). We found a statistically significant difference in the average value of GFR between the two sexes: men $(76 \pm 24.0)$ and women $(62.7 \pm 23.6), \mathrm{t}(168)=-3.435 ;(\mathrm{p}=0.001)$, respectively. We did not find a correlation between average GFR and diagnosis, but there was such a difference for the group with GFR $<60 \mathrm{ml} / \mathrm{min}$. The number of patients with STEMI diagnosis with $\mathrm{GFR}<60 \mathrm{ml} / \mathrm{min}$ was significantly higher than the number of patients in the group with UAP $(\mathrm{p}=0.006)$, and those with NSTEMI had lower values of GFR than UAP $(p=0.041)$. In the subgroup analysis, a significant difference of GFR was found in the age groups $(p<0.001)$ : patients aged $30-39$ years towards patients within the range 60-69, and 7079 years or over 80 years. No association was found between the average value of creatinine and GFR with nosocomial mortality $(p=0.3)$.
Rhythm or conduction disorders or both were found in $57(33.1 \%)$ of the patients. The most frequent arrhythmia was atrial fibrillation - 19 (11.0\%), represented by the highest percentage in the group with AMI with ST-elevation (9.7\%), followed by ventricular tachycardia in 7 (4.1\%). The highest proportion of conductive disorders included atrioventricular block - 13 (7.6\%), followed by the right bundle branch block 8 (4.7\%).

Of the echocardiography parameters measured at hospitalization, mitral insufficiency was more frequent in the group with STEMI vs. UAP $(p=0.002)$. The gravity of the mitral insufficiency did not correlate with the diagnosis of our study $(\mathrm{p}=0.8)$. The ejection fraction (EF) measured at hospitalization did not differ significantly in the three groups either, as the EF was not significantly lower, depending on the onset of chest pain $(p=0.12)$, regardless of the presence of single-vessel, two-vessel, and threevessel disease $(\mathrm{p}=0.38, \mathrm{p}=0.62, \mathrm{p}=0.38)$.

During hospitalization, 19 patients $(11 \%)$ were found with cardiac asthma, eight patients (4.7\%) had pulmonary edema, and 27 (15.7\%) were with cardiogenic shock. 
The cumulative nosocomial mortality was $7.6 \%$. Cardiac arrest was registered in 13 patients (7.6\%). There was a statistically significant correlation between the presence of LVHF and the death during hospitalization $(\mathrm{p}=0.017)$, regardless of the failed vessel (LM, LAD, LCx, RCA), as a cause for ACS. No significant correlation was found between the onset of the chest pain and the registered LVHF on admission to the hospital $(p=0.3)$. No correlation was found between the value of TnI and CPK-MB, both depending on the intervened failed vessel and nosocomial mortality.

The risk of nosocomial mortality was significantly higher in women $\left(\chi^{2}(2)=6.576\right.$; $\mathrm{p}=0.037)$. Significantly more women $(28.8 \%)$ were exposed to high risk than men $(13.3 \%)$. The highest chance of nosocomial mortality was registered in patients from the STEMI group compared to the other two groups $-\chi^{2}(4)=11.882$; $\mathrm{p}=0.018$. Significantly more patients with UAP $(70.5 \%)$ were exposed to lower risk than patients with STEMI (46.6\%) and NSTEMI (40.0\%). A statistically significant difference was found between the risk from nosocomial mortality regarding the treatment outcome $-\chi 2(2)=24.852$; $\mathrm{p}<0.001$. The number of patients who survived (55.3\%) had been at low risk, while deceased patients (69.2\%) were exposed to high risk. A statistical significance was found for the risk of mortality on the 6th month after the acute event between the sexes $-\chi 2(2)=6.004 ; p=0.048$. Significantly more women $(47.5 \%)$ were found at higher risk than men $(29.2 \%)$.

There was a strong connection between the risk of mortality at the 6th month after discharge from hospital compared to the diagnosis $-\chi^{2}(4)=17.514 ; p=0.002$. Significantly more patients with UAP (45.5\%) were exposed to low risk $(<89)$ compared to patients with STEMI (17.5\%). A significant correlation was found between the calculated GRACE-score and treatment outcome $-\chi^{2}(2)=15.145 ; \mathrm{p}=0.001$. Significantly more surviving patients $(25.8 \%)$ were exposed to low risk ( $<89$ points), while no low risk was identified among the deceased patients. Significantly more deceased patients (84.6\%) had been exposed to high risk $(>118$ points), as compared to those who survived (31.4\%).

The cumulative survival during the 1 st year was $82 \%$, in the 2 nd year it was $79 \%$, at the 3 rd - $76 \%$ (Figure 1). At the end of the third and the fifth year of the follow-up, the survived patients were respectively 126 and $118(74.1 \%, 69.4 \%)$, and those that had not survived were 44 (25.9\%) and $52(30.6 \%)$, respectively.

Related to the diagnosis, the cumulative survival during the first year was as follows: STEMI $-75 \%$, NSTEMI - 88\%, UA - 93\%.

The analysis of the variables shows that advanced age $(\mathrm{p}=0.005, \mathrm{OR}=1.024)$,

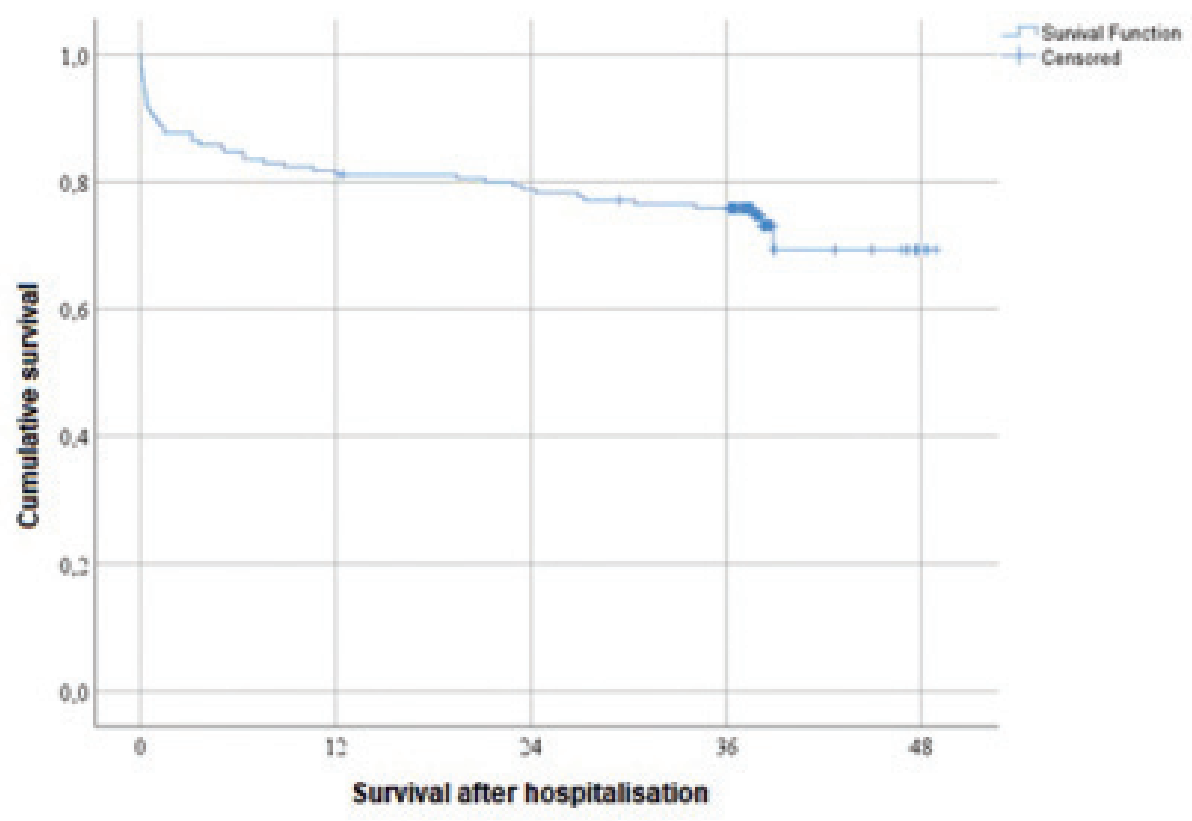

Figure 1. The overall survival curve for a period of 48 months 
experienced myocardial infarction $(\mathrm{p}=0.006$, $\mathrm{OR}=3.066$ ), three-vessel coronary disease $(\mathrm{p}=0.008, \mathrm{OR}=2.571), \quad$ glomerular filtration $<90 \mathrm{ml} / \mathrm{h}(\mathrm{p}=0.006, \mathrm{OR}=0.964)$, GRACE-score $>140 \mathrm{pt}(\mathrm{p}<0.001, \mathrm{OR}=1.045)$, HF (Killip's class $>=\mathrm{II})(\mathrm{p}=0.002, \mathrm{OR}=15.6)$ are factors for adverse prognosis at the first and the fifth year after ACS. Only the GRACE-score is an independent predictor of death, as demonstrated by multiregression analysis in the study $(\mathrm{p}=0.002, \mathrm{OR}=1.052) .($ Table 5$)$

At the $60^{\text {th }}$ month (the $5^{\text {th }}$ year), after dichotomizing, the analyzed variables changed their significance as predictive factors - Table 6 .

In the 9th year of the follow-up, the overall mortality is $39.2 \%$ (67), the patients surviving were $61.2 \%$ (104). The risk factors: diabetes mellitus, dyslipidemia, and smoking were poor prognostic markers for long-term survival. In smokers, the probability of adverse outcomes was 4.5 times higher compared to non-smokers in the 9th year. The presence of advanced age, diabetes mellitus, CKD, experienced AMI were predictors for poor prognosis. The univariant analysis of the variables in the 9th year of the follow-up is shown in the table below (Table 7).

Ejection fraction is a prognostic marker in the 12th, 60th, and 98th months of the follow-up. Patients with decreased systolic function $(\mathrm{EF}<40 \%)$ had poorer survival $(p=0.006, p=0.006, p=0.015)$. Patients with a decreased systolic function of the left ventricle (EF $<40 \%$ ) and three-vessel coronary disease tended to have poorer survival and prognosis $(\mathrm{p}$ $=0.003$ ) as compared to those without decreased EF or three-vessel coronary disease. (Tables 6 and 7).

Table 5. Univariant analysis of the 1st year after discharge from hospital

\begin{tabular}{|c|c|c|}
\hline Factor & $\begin{array}{l}\text { Univariant analysis } \\
\text { (p-value) }\end{array}$ & $\begin{array}{l}\text { Univariant analysis } \\
\text { (p-value) }\end{array}$ \\
\hline Sex & 0.649 & \\
\hline Women & & 1 \\
\hline Men & & $0.819(0.347 ; 1.934)$ \\
\hline Diagnosis & 0.029 & \\
\hline STEMI & & 1 \\
\hline NAP & & $4.260(1.210 ; 14.997)$ \\
\hline NSTEMI & & $3.584(0.787 ; 16.320)$ \\
\hline Age & 0.011 & $0.954(0.920 ; 0.989)$ \\
\hline Dyslipidemia & 0.972 & \\
\hline No & & 1 \\
\hline Yes & & $1.015(0.445 ; 2.313)$ \\
\hline Smoking & 0.916 & \\
\hline Non-smoker & & 1 \\
\hline Ex & & $1.387(0.285 ; 6.756)$ \\
\hline Smoker & & $1.088(0.457 ; 2.588)$ \\
\hline LDL-C & 0.433 & $1.140(0.822 ; 1.580)$ \\
\hline HDL & 0.731 & $1.189(0.443 ; 3.186)$ \\
\hline Triglyceride & 0.933 & $1.020(0.648 ; 1.604)$ \\
\hline Creatinine & 0.044 & $0.995(0.991 ; 1.000)$ \\
\hline Anemia & 0.267 & \\
\hline No & & 1 \\
\hline Yes & & $0.533(0.176 ; 1.619)$ \\
\hline Glomerular filtration & 0.014 & $1.022(1.005 ; 1.040)$ \\
\hline GRACE score & $<0.001$ & $0.975(0.963 ; 0.987)$ \\
\hline Acute left-sided heart failure & 0.006 & \\
\hline No & & 1 \\
\hline
\end{tabular}


-Doneva-Basheva K, et al. Predictors for long-term prognosis after acute coronary syndrome

\begin{tabular}{lll}
\hline Yes & & $0.045(0.005 ; 0.416)$ \\
\hline Diabetes mellitus & 0.286 & 1 \\
\hline No & & $0.627(0.267 ; 1.476)$ \\
\hline Yes & 0.838 & 1 \\
\hline Stable angina pectoris & $0.920(0.414 ; 2.047)$ \\
\hline No & \\
\hline Yes & 0.039 & 1 \\
\hline Experienced AMI & & $0.379(0.151 ; 0.953)$ \\
\hline No & \\
\hline Yes & 0.006 & 1 \\
\hline Ejection fraction (EF) & & $4.561(1.539 ; 13.514)$ \\
\hline$<40 \%$ & \\
\hline$>=40 \%$ & 0.788 & 1 \\
\hline Cerebrovascular disease & $1.238(0.261 ; 5.864)$ \\
\hline No & \\
\hline Yes & 1 \\
\hline Killip-II-IV & 0.838 & $0.895(0.308 ; 2.598)$ \\
\hline No &
\end{tabular}

Table 6. Univariant analysis of the 5th year after discharge from hospital

\begin{tabular}{|c|c|c|}
\hline Factor & $\begin{array}{l}\text { Univariant analysis } \\
\text { (p-value) }\end{array}$ & $\begin{array}{l}\text { Univariant analysis } \\
\text { (p-value) }\end{array}$ \\
\hline Sex & 0.495 & \\
\hline Women & & 1 \\
\hline Men & & $1.266(0.643 ; 2.493)$ \\
\hline Diagnosis & 0.125 & \\
\hline STEMI & & 1 \\
\hline NAP & & $2.386(1.001 ; 5.689)$ \\
\hline NSTEMI & & $0.943(0.378 ; 2.351)$ \\
\hline Age & $<0.001$ & $0.940(0.911 ; 0.970)$ \\
\hline Dyslipidemia & 0.241 & \\
\hline No & & 1 \\
\hline Yes & & $1.489(0.766 ; 2.898)$ \\
\hline Smoking & 0.031 & \\
\hline Non-smoker & & 1 \\
\hline Ex & & $1.250(0.394 ; 3.962)$ \\
\hline Smoker & & $2.841(1.306 ; 6.181)$ \\
\hline LDL-C & 0.166 & $1.215(0.923 ; 1.600)$ \\
\hline HDL & 0.278 & $1.574(0.694 ; 3.571)$ \\
\hline Triglyceride & 0.424 & $1.171(0.795 ; 1.725)$ \\
\hline Creatinine & $<0.001$ & $0.976(0.964 ; 0.988)$ \\
\hline Anemia & 0.102 & \\
\hline No & & 1 \\
\hline
\end{tabular}


J Biomed Clin Res Volume 14 Number 1, 2021

\begin{tabular}{|c|c|c|}
\hline Yes & & $0.447(0.170 ; 1.175)$ \\
\hline Glomerular filtration & $<0.001$ & $1.036(1.019 ; 1.053)$ \\
\hline GRACE score & $<0.001$ & $0.973(0.962 ; 0.985)$ \\
\hline Acute left-sided heart failure & 0.044 & \\
\hline No & & 1 \\
\hline Yes & & $0.103(0.011 ; 0.941)$ \\
\hline Pon_poly & 0.541 & \\
\hline LL & & 1 \\
\hline LM & & $0.648(0.239 ; 1.756)$ \\
\hline MM & & $1.296(0.273 ; 6.155)$ \\
\hline Diabetes mellitus & 0.007 & \\
\hline No & & 1 \\
\hline Yes & & $0.377(0.185 ; 0.769)$ \\
\hline Stable angina pectoris & 0.184 & \\
\hline No & & 1 \\
\hline Yes & & $0.640(0.311 ; 1.237)$ \\
\hline Experienced AMI & $<0.001$ & \\
\hline No & & 1 \\
\hline Yes & & $0.217(0.096 ; 0.493)$ \\
\hline Ejection fraction (EF) & 0.006 & \\
\hline$<40 \%$ & & 1 \\
\hline$>=40 \%$ & & $4.472(1.528 ; 13.086)$ \\
\hline Cerebrovascular disease & 0.673 & \\
\hline No & & 1 \\
\hline Yes & & $0.781(0.248 ; 2.459)$ \\
\hline Killip-II-IV & 0.553 & \\
\hline No & & 1 \\
\hline Yes & & $1.325(0.523 ; 3.361)$ \\
\hline
\end{tabular}

Table 7. Univariant analysis of the variables at the 9th year of the follow-up

\begin{tabular}{lll}
\hline Factor & $\begin{array}{l}\text { Univariant analysis } \\
(\mathrm{p} \text {-value })\end{array}$ & $\begin{array}{l}\text { Univariant analysis } \\
(\mathrm{p} \text {-value })\end{array}$ \\
\hline Sex & 0.307 & 1 \\
\hline Women & $1.398(0.735 ; 2.662)$ \\
\hline Men & \\
\hline Diagnosis & 0.090 & 1 \\
\hline STEMI & & $2.411(1.097 ; 5.297)$ \\
\hline NAP & $1.205(0.494 ; 2.939)$ \\
\hline NSTEMI & \\
\hline Age & $0.920(0.891 ; 0.951)$ \\
\hline Dyslipidemia & \\
\hline No & $<0.001$ & 1 \\
\hline
\end{tabular}


-Doneva-Basheva K, et al. Predictors for long-term prognosis after acute coronary syndrome

\begin{tabular}{|c|c|c|}
\hline Yes & & $1.716(0.910 ; 3.236)$ \\
\hline Smoking & $<0.001$ & \\
\hline Non-smoker & & 1 \\
\hline Ex & & $2.233(0.707 ; 7.049)$ \\
\hline Smoker & & $4.558(2.145 ; 9.684)$ \\
\hline LDL-C & 0.134 & $1.214(0.942 ; 1.564)$ \\
\hline HDL & 0.999 & $0.999(0.471 ; 2.119)$ \\
\hline Triglyceride & 0.130 & $1.340(0.918 ; 1.955)$ \\
\hline Creatinine & $<0.001$ & $0.970(0.957 ; 0.983)$ \\
\hline Anemia & 0.027 & \\
\hline No & & 1 \\
\hline Yes & & $0.328(0.122 ; 0.883)$ \\
\hline Glomerular filtration & $<0.001$ & $1.044(1.027 ; 1.062)$ \\
\hline GRACE score & $<0.001$ & $0.964(0.950 ; 0.977)$ \\
\hline Acute left-sided heart failure & 0.094 & \\
\hline No & & 1 \\
\hline Yes & & $0.150(0.016 ; 1.377)$ \\
\hline Pon_poly & 0.334 & \\
\hline LL & & 1 \\
\hline LM & & $0.522(0.195 ; 1.395)$ \\
\hline MM & & $1.125(0.259 ; 4.893)$ \\
\hline Diabetes mellitus & 0.008 & \\
\hline No & & 1 \\
\hline Yes & & $0.390(0.195 ; 0.784)$ \\
\hline Stable angina pectoris & 0.529 & \\
\hline No & & 1 \\
\hline Yes & & $0.820(0.442 ; 1.521)$ \\
\hline Experienced AMI & 0.001 & \\
\hline No & & 1 \\
\hline Yes & & $0.260(0.114 ; 0.590)$ \\
\hline Ejection fraction (EF) & 0.015 & \\
\hline$<40 \%$ & & 1 \\
\hline$>=40 \%$ & & $3.952(1.305 ; 11.971)$ \\
\hline Cerebrovascular disease & 0.053 & \\
\hline No & & 1 \\
\hline Yes & & $0.324(0.103 ; 1.015)$ \\
\hline Killip-II-IV & 0.791 & \\
\hline No & & 1 \\
\hline Yes & & $0.893(0.386 ; 2.066)$ \\
\hline
\end{tabular}

\section{Discussion}

Throughout the years, many models of close and long survival of patients after ACS have been reported. Most of the studies include patients in selected groups, excluding persons with comorbidities and at an advanced age. In this study, we included patients from real clinical 
practice consecutively hospitalized with ACS. Our results approximate those in the literature $[10,11,12,13]$. The age of an acute coronary event was approximately five years earlier in men than in women. Arterial hypertension was a more frequent risk factor among Bulgarian patients compared to the published data. In our group, arterial hypertension, dyslipidemia, smoking, diabetes mellitus, and family history were more frequent in men than reported in other studies.

The cumulative nosocomial mortality was $7.6 \%$. The overall survival and mortality during the 1 st years were $82.9 \%$ (141) and $17.1 \%$, respectively [28]. At the end of the third and the fifth year of the follow-up, the survived patients were respectively 126 and 118 (74.1\%, 69,4\%), and those that had not survived were $44(25.9 \%)$ and $52(30.6 \%)$. In the 9 th year of the followup, the overall mortality was $67(39.2 \%)$, and the patients who survived were 104 (61.2\%). In the 12th month, we identified eight predictors for poor prognosis, stratified by diagnosis, age, creatinine value, GFR, GRACE-score, presence of acute left-sided heart failure on admission, experienced myocardial infarction, and $\mathrm{EF}<40 \%$. Over the five years, the predictors remained the same, regardless of the diagnosis, and the presence of smoking and diabetes mellitus worsened the survival rate. The Brazilian study ERICO reported $12 \%$ one-year mortality after ACS [14]. The study included a sample of individuals with different social-economical status: 269 (27.9\%) persons with STEMI, 378 (39.2\%) with NSTEMI, and 317 (32.9\%) with UA, who were followed up in the $1 \mathrm{st}, 6 \mathrm{th}$, and 12th months using questionnaires on the phone. The researchers found a high frequency of $\mathrm{AH}$ $(77.2 \%)$, dyslipidemia $(54.9 \%)$ and diabetes mellitus (39.6\%), and physical inactivity $(71.9 \%$ [14].

The persons with a history of acute myocardial infarction are exposed to increased risk of future cardiovascular incidents (repeated AMI, heart failure, life-threatening arrhythmia, CV death) $[10,15,16,17]$. The increased risk of recurrent $\mathrm{CV}$ incidents draws attention to studies on survival and prognosis in patients with AMI, focused on the acute phase throughout the 1st year [18]. A systematic review for identifying the epidemiological studies of long-term $(\geq$ 10-years) tendencies for incidence and mortality in persons who experienced AMI more than one year was published by Renet al. [18]. The authors analyzed the relative risk of all causes of death after the first year from a study in Denmark, in which the patients were randomized in two groups - healthy ( $>30$ years) without data for diabetes mellitus and history of AMI, and a second group - patients with experienced ACS $[18,19]$. The relative risk of all causes $\mathrm{f}[$ of death increased to 1-3 years and 3-5 years after AMI, compared to the reference population, and was higher in women than in men $[18,19]$. These data are supported by a meta-analysis including $>100000$ persons aged over 65 years, demonstrating a higher risk during the first year after experienced AMI [20]. Although the risk was lower during the next three years than during the first year, it remained relatively high, and approximately one of five patients who had not had a combined endpoint during the first year had a fatal AMI, a non-fatal stroke, or death for cardiac reasons during the next three years [11]. During the 1st year, approximately one-third of the patients had experienced repeated AMI, stroke, or death for cardiac reasons $[10,20]$. The same study found an increased relative risk of recurring cardiovascular incidents up to the 5th year compared to the reference group, especially in women $[10,19]$. The presence of advanced age, smoking, $\mathrm{AH}$, diabetes mellitus, peripheral arterial disease, cardiovascular disease, CKD, COPD, hepatic insufficiency, and cancer increases the all-cause mortality in persons who experienced STEMI/NSTE-ACS [10,21]. Swedish data from the meta-analysis of 97254 has demonstrated $18.3 \%$ mortality in the first year $[11,24]$. The high risk of cardiovascular events after the first year implies continuous monitoring and secondary prevention, and continuous double anti-thrombosis therapy (DAPT) after the first year after AMI prevents vascular incidents [22]. In the DAPT study on patients treated by implanting a drug-eluting stent (DES), the continuous double anti-aggregation therapy after the 12th month leads to a significant decrease of the cumulative mortality at the expense of the frequency of late stent thrombosis, cardiovascular and cerebrovascular incidents during the next 18 months, as compared to monotherapy with acetylsalicylic acid [18,23]. The current ESC 
recommendations are DAPT for 12 months in case of secondary prevention, which could be extended for specific patients.

\section{Conclusion}

Our study results show that the identification on admission to a hospital of factors like old age, women, CKD, documented data for experienced AMI, systolic dysfunction of left ventricular, and three-vessel coronary disease represent risk factors in poor prognosis during hospital treatment and after discharge. The presence of these factors on admission could be of use for faster and earlier identifying high-risk patients. A disadvantage of our study is the lack of information about all causes of mortality. Such information could allow for more accurate identification of predictors of survival and mortality in patients with ACS.

\section{References}

1. Sanchis-Gomar F, Perez-Quilis C, Leischik R, Lucia A. Epidemiology of coronary heart disease and acute coronary syndrome. Ann Transl Med. 2016;4(13):256.

2. Mahmood S, Levy D, Vasan R, Wangb T. The Framingham Heart Study and the Epidemiology of Cardiovascular Diseases: A HistoricalPerspective. Lancet. 2014;383(9921):999-1008.

3. Splansky GL, Corey D, Yang Q, et al. The third generation cohort of the National Heart, Lung, and Blood Institute's Framingham Heart Study: design, recruitment, andinitial examination. Am J Epidemiol. 2007;165:1328-35.

4. Kannel W, Dawber T, Cohen M, McNamara P. Vascular disease of the Brain-Epidemiologic Aspects: the Farmingham Study. Am J Public Health Nations Health. 1965;55:1355-66

5. Wilson P, D'Agostino R, Levy D, Belanger A, Silbershatz H, Kannel W. Prediction of coronary heartdisease using risk factor categories. Circulation. 1998;97:1837-47.

6. Tatu-Chitoiu G, Cinteza M, Dorobantu M, Udeanu M, et al. In-hospital case fatality rates for acute myocardial infarction in Romania. CMAJ. 2009;180(12):1207-13.

7. Brezinov O, Klempfner R, Zekry S, Goldenberg I, Kuperstein R. Prognostic value of ejection fraction in patients admitted with acute coronary syndrome. Medicine. 2017;96(9):e6226.

8. Dyakova M, Shipkovenska E, Dyakov P,
Dimitrov P, Torbova S. Cardiovascular Risk Assessment of Bulgarian Urban Population: Cross-SectionalStudy. CroatMed J. 2008;49(6):783-91.

9. Kanazirev B. Survival and prognosis in patients with symptomatic heart failure and disturbed left ventricle systolic and segment function. Science Cardiology. 2011(2):69-73.

10. Ren L, Ye H, Wang P, Cui Y, Cao S. Comparison of long-term mortality of acute ST-segment elevation myocardial infarction and non-ST-segment elevation acute coronary syndrome patients after percutaneous coronary intervention. Int $\mathrm{J}$ Clin Exp Med. 2014;7(12):5588.

11. Jernberg T, Hasvold P, Henriksson M, Hjelm H, Thuresson M, Janzon M. Cardiovascular risk in post-myocardial infarction patients: nationwide real world data demonstrate the importance of a long-term perspective. Eur Heart J. 2015;36(19):1163-70.

12. Lee D, Jeong M, Rhee J, Choi J, Lee K, Lee M. And al. Predictors of Long-Term Survival in Acute Coronary Syndrome Patients With Left Ventricular Dysfunction After Percutaneous Coronary Intervention. Korean Circ J. 2012;42(10):692-7.

13. Plakht Y, Shiyovich A, Gilutz H. Predictors of long-term (10-year) mortality postmyocardial infarction: Age-related differences. Soroka Acute Myocardial Infarction (SAMI) Project. Cardiology J. 2015;65(3):216-23.

14. Santos L, Goulart A, Brandao R, Santos R, Bittencourt M, Sitnik D, \& Bensenor I. Oneyear mortality after an acute coronary event and its clinical predictors: The ERICO Study. Arq Bras Cardio. 2015;105(1):53-64.

15. Smolina K, Wright FL, Rayner M, Goldacre MJ. Long-term survival and recurrence after acute myocardial infarction in England, 2004 to 2010. Circ Cardiovasc Qual Outcomes. 2012;5(4):532-40.

16. Witt BJ, Brown RD, Jr, Jacobsen SJ, Weston SA, Yawn BP, Roger VL. A community-based study of stroke incidence after myocardial infarction. Ann Intern Med. 2005;143(11):785-92.

17. Campo G, Saia F, Guastaroba P, Marchesini J, Varani E, Manari A, Ottani F, Tondi S, De Palma R, Marzocchi A. Prognostic impact of hospital readmissions after primary percutaneous coronary intervention. Arch Intern Med. 2011;171(21):1948-9.

18. Ren L, Ye H, Wang P, Cao S. Comparison of longterm mortality of acute ST-segment elevation myocardial infarction and non-ST-segment elevation acute coronary syndrome patients after percutaneous coronary intervention. Int $\mathbf{J}$ 
ClinExp Med. 2014;7(12):5588-92.

19. Norgaard ML, Andersen SS, Schramm TK, Folke F, Jorgensen CH, Hansen ML, Andersson C, Bretler DM, Vaag A, Kober L, et al. Changes in short- and long-term cardiovascular risk of incident diabetes and incident myocardial infarction--a nationwide study. Diabetologia. 2010;53(8):1612-9.

20. Rapsomaniki E, Thuresson M, Yang E, Blin P, Hunt P, Chung SC, Stogiannis D, PujadesRodriguez M, Timmis A, Denaxas SC, et al. Using big data from health records from four countries to evaluate chronic disease outcomes: a study in 114364 survivors of myocardial infarction. Eur Heart J. 2016;2(3):172-83.

21. Rapsomaniki E, Shah A, Perel P, Denaxas S, George J, Nicholas O, Udumyan R, Feder GS, Hingorani AD, Timmis A, et al. Prognostic models for stable coronary artery disease based on electronic health record cohortof 102023 patients. EurHeart J. 2014;35(13):844-52.

22. Fox K, Carruthers K, Dunbar D, Graham C, Manning J, Raedt H, Buysschaert I, Lambrechts D, Van de Werf F. Underestimated and underrecognized: the late consequences of acute coronary syndrome (GRACE UK-Belgian Study). Eur Heart J, 2010;31:2755-64.

23. Mauri L, Kereiakes DJ, Yeh RW, DriscollShempp P, Cutlip DE, Steg PG, Normand SL, Braunwald E, Wiviott SD, Cohen DJ, et al. Twelve or 30 months of dual antiplatelet therapy after drug-eluting stents. N Engl J Med. 2014;371(23):2155-66.

24. Kiani F, Hesabi N, ArbabisarjouA.Assessment of risk factorsin patients with myocardialinfarction. Glob J Health Sci. 2016;8(1):255-62.

25. Anand S, Islam S, Rosengren A, Franzosi M, Steyn K, Yusufali A, Yusuf S. Risk factors for myocardial infarction in women and men: in sights from the INTERHEART study. EHJ. 2008;29(7):932-40.

26. 2012 ACCF/AHA Focused Update of the Guideline for the Management of Patients With Unstable Angina/Non-ST-Elevation Myocardial Infarction (Updating the 2007 Guideline and Replacing the 2011 Focused Update). A Report of the American College of Cardiology Foundation/American Heart Association Task Force on Practice Guidelines. Circulation. 2012;126:875-910.
27. Roffi M, Patrono C, Collet J, Mueller C, Valgimigli M, Andreotti F, et al. 2015 ESC Guidelines for the management of acute coronary syndromes in patients presenting without persistent ST-segment elevation Web Addenda Task Force for the Management of Acute Coronary Syndromes in Patients Presenting without Persistent ST-Segment Elevation of the European Society of Cardiology (ESC) 51. ESC Guidelines for the management of acute coronary syndromes in patients presenting without persistent ST-segment elevation - Web Addenda; Task Force for the Management of Acute Coronary Syndromes in Patients Presenting without Persistent STSegment Elevation of the European Society of Cardiology (ESC);2015.EHJ 1:3-13.

28. Parkhomenko A, Dovgan N, Lutay Y, Kozhukhov S. Markersof poor prognosisinNonST segment elevation acute coronary syndromes without revascularization: A 3-year Survival Analysis. JMRI. 2018;2(2):1-6.

29. Numasawa Y, Kohsaka S, Miyata H, et al. Gender Differences in In-Hospital Clinical Outcomes after Percutaneous Coronary Interventions: An Insight from a Japanese Multicenter Registry. PLoS One. 2015;10(1):e0116496.

30. Vasilevski N, Tsolova G, Dimitrov P, Manolova A. Surveillance of risk factors for noncommunicable diseases among population aged 25-64 within the zones of CINDI programme Bulgaria. Bulgarian Journal of Public Health. 2010;2:3-34.

31. Guo Y, Yin F, Fan C, Wang Z. Gender difference in clinical outcomes of the patients with coronary artery disease after percutaneous coronary intervention. A systematic review and meta-analysis. Medicine (Baltimore). 2018;97(30):e11644. 